\title{
LABORATORY SUPPORT FOR THE DIAGNOSIS AND SURVEILLANCE OF SEXUALLY TRANSMITTED INFECTIONS
(STIS) IN EASTERN EUROPE
}

\author{
M Domeika (marius.domeika@medsci.uu.se) ${ }^{1}$, M Unemo², R C Ballard ${ }^{3}$, on behalf of the Eastern European Network for Sexual \\ and Reproductive Health (EE SRH Network)
}

1. Department of Medical Sciences, Uppsala University, Uppsala/Eastern European Committee of Swedish Health Care Community, Stockholm, Sweden

2. Swedish Reference Laboratory for Pathogenic Neisseria, Department of Laboratory Medicine, Clinical Microbiology, Örebro University Hospital, Örebro, Sweden

3. Division of STD Prevention, Centers for Disease Control and Prevention (CDC), Atlanta, United States

This article was published on 1 October 2009.

Citation style for this article: Domeika M, Unemo M, Ballard RC, on behalf of the Eastern European Network for Sexual and Reproductive Health (EE SRH Network). Laboratory support for the diagnosis and surveillance of sexually transmitted infections (STIs) in Eastern Europe. Euro Surveill. 2009;14(39):pii=19340. Available online: http://www. eurosurveillance.org/ViewArticle.aspx?ArticleId $=19340$

This report outlines the proceedings of the 4th Annual Meeting of the Eastern European Network for Sexual and Reproductive Health (EE SRH Network) [1,2], which took place at Uppsala University in Uppsala, Sweden between 30 May and 3 June, 2009. The meeting was attended by 65 network participants from 14 Eastern European countries (Armenia, Azerbaijan, Belarus, Bulgaria, Estonia, Georgia, Hungary, Kazakhstan, Kyrgyzstan, Lithuania, Russian Federation, Ukraine, Uzbekistan and Tajikistan), representatives of the World Health Organization (WHO) and invited experts from Sweden, United States, Denmark, and United Kingdom. The plenary session was followed by workshops on: (a) the development of sexually transmitted infections (STI) laboratory diagnosis guidelines, (b) surveillance of antimicrobial resistance of Neisseria gonorrhoeae and (c) epidemiological surveillance systems.

During the conference, it was emphasised, that STIs remain an unrecognised, but significant public health problem in the majority of Eastern European (EE) countries. WHO in its "Global strategy for prevention and control of STIs for 2006-2015" states that it is crucial to increase the commitment of national governments and to use integrated approaches in order to address the problem [3]. The EE SRH Network has endorsed these aims and contributed to the work of WHO by promoting cooperation on both national and regional levels and by developing international consensus approaches for the diagnosis of STIs [4].

It has long been recognised that laboratory testing plays an essential role in patient management and epidemiological surveillance of STIs. However, a survey of laboratory diagnostic methods among the network countries demonstrated that individual tests and approaches used to establish a diagnosis often do not achieve recommended international standards. For example, serological tests are used to diagnose chlamydial infection in up to $70 \%$ of clinical laboratories in several EE countries, while screening for gonococcal infections in women is largely conducted by using microscopy of Gram-stained cervical smears. In addition, few laboratories use type-specific herpes simplex virus (HSV) serology for the diagnosis of genital herpes [5].
In order to improve the quality of STI diagnostic services in the region, the EE SRH network has prepared "consensus" guidelines for the laboratory diagnosis of gonorrhoea, syphilis and chlamydial infections. These guidelines were formulated by the network participants during previous meetings, using evidencebased principles. This approach stimulated direct communication between leading experts from "East" and "West", resulting in consensus documents which were first published internationally [6-8] and then subsequently adopted and published at the national level $[1,2]$.

During the meeting reported here, workshop participants reached consensus on further guidelines for the laboratory diagnosis of four specific infections, namely, bacterial vaginosis (BV), infections caused by Mycoplasma genitalium, trichomoniasis and genital herpes. International and national publications of these guidelines are currently in preparation [9].

It is recognised that both the quality of test kits used and the implementation of quality assurance systems contribute to the confidence in results provided and reputation of diagnostic services. STI diagnostic test kits manufactured in EE countries have rarely been internationally validated. The network has conducted a number of studies comparing Russian-manufactured tests for the detection of $N$. gonorrhoeae, Chlamydia trachomatis and Mycoplasma genitalium with internationally acknowledged methods, which yielded promising results [10-13]. It is clear that the regional biomedical industry has the potential for producing reliable reagents and tests kits at affordable prices; however, strict quality assurance is crucial [14]. Comprehensive evaluations of locally manufactured tests should be conducted according to internationally accepted guidelines as a prerequisite to marketing products in the region. In addition, other issues related to laboratory quality assurance have emerged as a high priority for many $E E$ countries. The establishment of an extensive external quality assurance programme for the serological diagnosis of syphilis in Russia has revealed a number of difficulties, including lack of willingness to participate and high rates of false-positive/negative 
results [15]. Such programmes should be extended to include all laboratory testing, with appropriate sanctions being implemented for those laboratories that consistently fail to provide satisfactory results.

Another factor which is necessary to assure high-quality laboratory practices is the establishment of national or regional reference laboratories for STIs, preferably supported and financed by the state authorities. At present, there are no such institutions in Eastern Europe. Such institutions could provide a source of expertise to support national or regional STI initiatives, perform reference testing and collect surveillance data. In addition, these laboratories could maintain external quality assurance (EQA) programmes, supervise updating of national STI laboratory guidelines and establish international collaborations [16].

The emergence and spread of antimicrobial resistance (AMR) among isolates of $N$. gonorrhoeae is recognised as a major concern globally. However, in the majority of the EE countries AMR testing of $N$. gonorrhoeae isolates is performed only occasionally, because gonococcal culture is rarely undertaken [17]. At the EE SRH meeting, a workshop to establish AMR surveillance of $N$. gonorrhoeae in the network countries was conducted at the Swedish Reference Laboratory for Pathogenic Neisseria (Örebro University Hospital). Representatives from Russia, Belarus, Estonia, Georgia, Ukraine and Kazakhstan adopted WHO protocols regarding culture, identification and AMR testing for $N$. gonorrhoeae and received $\mathrm{WHO}$ quality control strains and reagents to enable them to initiate collection of $N$. gonorrhoeae strains for AMR testing. The remaining countries will be supported in order to overcome some technical difficulties before the collection of strains can commence.

Most EE countries inherited complicated and labour-intensive communicable disease surveillance systems. STI surveillance is mostly suboptimal owing to old-fashioned, non-standardised, paperbased surveillance systems and the absence of computer-based statistical tools [18]. Furthermore, legal constraints have shown to be a potential barrier for good STI surveillance [19]. Surveillance systems for STIs differ from one country to another depending on the availability of laboratory services and the accessibility of healthcare-provider institutions. However, all countries should strive to nationwide establish, implement, and maintain as high quality laboratory service as possible considering resource constraints [20].

During a one-day epidemiological surveillance workshop, participants were introduced to a computer-based system for communicable disease surveillance (ULISAS), developed as a result of a joint Lithuanian-Swedish project [21]. Lithuanian and Belarusian epidemiologists presented their recent experiences with this programme. The system is already being used as a national tool in Lithuania; while in Belarus, it has been fully implemented in the capital, Minsk and is currently being introduced in other parts of the country [22]. Discussions on the adaptation and implementation of the system by other EE SRH countries are in progress.

\section{Acknowledgements}

This project is supported by grants from the Swedish International Development Cooperation Agency (Styrelsen för Internationellt Utvecklingssamarbete, SIDA), via East Europe Committee of the Swedish Health Community, Stockholm, Sweden.

\section{References}

1. Domeika M, Savicheva A, Sokolovskiy E, Ballard R, Unemo M. Guidelines for laboratory diagnosis of Neisseria gonorrhoeae infections in Eastern European countries - results of an international collaboration. Euro Surveill. 2007;12(49):pii=3326. Available from: http://www.eurosurveillance.org/ ViewArticle.aspx?ArticleId $=3326$

2. Domeika M, Savicheva A, Sokolovskiy E, Ballard R, Unemo M; Eastern European Network for Sexual and Reproductive Health (EE SRH Network). Quality enhancements and quality assurance of laboratory diagnosis of sexually transmitted infections in Eastern Europe. Int J STD AIDS. 2009;20(5):365-7.

3. Ndowa F. The global strategy for prevention and control of sexually transmitted infections. Proceedings of the 4th Annual Meeting of the Eastern European Network for Sexual and Reproductive Health (EE SRH Network). Uppsala University, Uppsala, Sweden, 30 May - 03 June, 2009. Available from: http:// www.medsci.uu.se/klinbakt/stigup/Projects/000\%20EE\%20SRH\%20N/09\%2006\%20 30\%20EE\%2OSRH\%2OMeting\%2OUppsala/07\%2010\%2013\%20CONF\%2OPRESENTATIONS. htm

4. Domeika M. Quality enhancement of the management of sexually transmitted infections (STIs) in Eastern Europe by the means of the EE SRH network. Proceedings of the 4th Annual Meeting of the Eastern European Network for Sexual and Reproductive Health (EE SRH Network). Uppsala University, Uppsala, Sweden, 30 May - 03 June, 2009. Available from: http://www.medsci.uu.se/ klinbakt/stigup/Projects/000\%20EE\%20SRH\%20N/09\%2006\%2030\%20EE\%20SRH\%20 Meting\%20Uppsala/07\%2010\%2013\%20CONF\%2OPRESENTATIONS.htm

5. Brilene T. Laboratory diagnosis of STI in Eastern European countries. Proceedings of the 4th Annual Meeting of the Eastern European Network for Sexual and Reproductive Health (EE SRH Network). Uppsala University, Uppsala, Sweden, 30 May - 03 June, 2009. Available from: http://www.medsci.uu.se/ klinbakt/stigup/Projects/000\%20EE\%20SRH\%20N/09\%2006\%2030\%20EE\%20SRH\%2O Meting\%20Uppsala/07\%2010\%2013\%20CONF\%20PRESENTATIONS.htm

6. Savicheva A, Sokolovskiy E, Frigo N, Priputnevich T, Brilene T, Deak J, et al. Guidelines for laboratory diagnosis of Neisseria gonorrhoeae in Eastern European Countries. Acta Medica Lithuanica, 2007, 4: 67-74 (Part 1) and 123134 (Part “2). Available from: http://images.katalogas.lt/maleidykla/Act71/ ActaMed14_065-074.pdf and http://images.katalogas.lt/maleidykla/Act72/ Act_123_134.pdf

7. Domeika M, Savicheva A, Sokolovskiy E, Frigo N, Brilene T, Hallén A, et al Guidelines for the laboratory diagnosis of Chlamydia trachomatis infections in East European countries. J Eur Acad Dermatol Venereol. 2009 Jun 1. [PMID: 19522706; Epub ahead of print]

8. Sokolovskiy E, Frigo N, Rotanov S, Savicheva A, Dolia O, Kitajeva N, et al. Guidelines for the laboratory diagnosis of syphilis in East European countries. J Eur Acad Dermatol Venereol. 2009;23(6):623-32.

9. Domeika M, Ballard R, Unemo M on behalf of the Eastern European Network for Sexual and Reproductive Health (EE SRH Network). Optimization, harmonization and quality assurance of the laboratory diagnosis of sexually transmitted infections in Eastern Europe. Proceedings for the 11th IUSTI World Congress, 9-12 November, 2009, Cape Town, South Africa.

10 Savicheva A. First experiences of quality evaluation for the diagnostic test systems produced in Eastern Europe. Proceedings of the 4th Annual Meeting of the Eastern European Network for Sexual and Reproductive Health (EE SRH Network). Uppsala University, Uppsala, Sweden, 30 May - 03 June, 2009. Available from: http://www.medsci.uu.se/klinbakt/stigup/Projects/000\%20EE\%20 SRH\%20N/09\%2006\%2030\%20EE\%20SRH\%2OMeting\%2OUppsala/07\%2010\%2013\%20 CONF\%2OPRESENTATIONS.htm

11. Shipitsyna E, Zolotoverkhaya E, Hjelmevoll SO, Maximova A, Savicheva A, Sokolovsky E, et al. Evaluation of six nucleic acid amplification tests used for diagnosis of Neisseria gonorrhoeae in Russia compared with an international strictly validated real-time porA pseudogene polymerase chain reaction. J Eur Acad Dermatol Venereol. 2009 Apr 30. [PMID: 19453773; E-pub ahead of print]

12. Shipitsyna E, Zolotoverkhaya E, Agné-Stadling I, Krysanova A, Savicheva A, Sokolovsky $E$, et al. First evaluation of six nucleic acid amplification tests widely used in the diagnosis of Chlamydia trachomatis in Russia. J Eur Acad Dermatol Venereol. 2009; 23(3):268-76.

13. Shipitsyna E, Zolotoverkhaya E, Dohn B, Benkovich A, Savicheva A, Sokolovsky E, et al. First evaluation of polymerase chain reaction assays used for diagnosis of Mycoplasma genitalium in Russia. J Eur Acad Dermatol Venereol. 2009; 23(10):1164-72

14. Guschin A. Perspectives of the commercial NAAT kits manufactured in Russia; elaboration of the quality control panels for the NAATs. Proceedings of the 4th Annual Meeting of the Eastern European Network for Sexual and Reproductive Health (EE SRH Network). Uppsala University, Uppsala, Sweden, 30 May - 03 June, 2009. Available from: http://www.medsci.uu.se/klinbakt/ stigup/Projects/000\%20EE\%2OSRH\%20N/09\%2006\%2030\%20EE\%20SRH\%2OMeting\%20 Uppsala/07\%2010\%2013\%20CONF\%2OPRESENTATIONS.htm 
15. Frigo N. First experience of external laboratory quality control for STIs: Russian Federal System for Syphilis Control. Proceedings of the 4th Annual Meeting of the Eastern European Network for Sexual and Reproductive Health (EE SRH Network). Uppsala University, Uppsala, Sweden, 30 May - 03 June, 2009. Available from: http://www.medsci.uu.se/klinbakt/stigup/Projects/000\%20EE\%20 SRH\%20N/09\%2006\%2030\%20EE\%20SRH\%20Meting\%20Uppsala/07\%2010\%2013\%20 CONF\%2OPRESENTATIONS.htm

16. Ballard R. The laboratory and STI surveillance. Proceedings of the 4th Annual Meeting of the Eastern European Network for Sexual and Reproductive Health (EE SRH Network). Uppsala University, Uppsala, Sweden, 30 May - 03 June, 2009. Available from: http://www.medsci.uu.se/klinbakt/stigup/Projects/000\%20EE\%20 SRH\%20N/09\%2006\%2030\%20EE\%20SRH\%20Meting\%2OUppsala/07\%2010\%2013\%20 CONF\%2OPRESENTATIONS.htm

17. Unemo M. Neisseria gonorrhoeae (GC) antimicrobial resistance (AMR) surveillance - global perspective and prospects in Eastern Europe. Proceedings of the 4th Annual Meeting of the Eastern European Network for Sexual and Reproductive Health (EE SRH Network). Uppsala University, Uppsala, Sweden, 30 May - 03 June, 2009. Available from: http://www.medsci.uu.se/ klinbakt/stigup/Projects/000\%20EE\%2OSRH\%20N/09\%2006\%2030\%20EE\%20SRH\%20 Meting\%20Uppsala/07\%2010\%2013\%20CONF\%2OPRESENTATIONS.htm

18. Fisenko E. Surveillance and surveillance systems for communicable diseases and STIs in Eastern Europe. Proceedings of the 4th Annual Meeting of the Eastern European Network for Sexual and Reproductive Health (EE SRH Network). Uppsala University, Uppsala, Sweden, 30 May - 03 June, 2009. Available from: http://www.medsci.uu.se/klinbakt/stigup/Projects/000\%20EE\%20SRH\%2O N/O9\%2006\%2030\%20EE\%20SRH\%2OMeting\%2OUppsala/07\%2010\%2013\%20CONF\%20 PRESENTATIONS.htm

19. Manukian E. STI management in Eastern Europe: legal aspects, patient management, surveillance. Proceedings of the 4th Annual Meeting of the Eastern European Network for Sexual and Reproductive Health (EE SRH Network). Uppsala University, Uppsala, Sweden, 30 May - 03 June, 2009. Available from: http://www.medsci.uu.se/klinbakt/stigup/Projects/000\%20EE\%20SRH\%20 N/O9\%2006\%2030\%20EE\%2OSRH\%2OMeting\%2OUppsala/07\%2010\%2013\%20CONF\%20 PRESENTATIONS.htm

20. Ballard R. The role of the reference laboratory in STI control. Proceedings of the 4th Annual Meeting of the Eastern European Network for Sexual and Reproductive Health (EE SRH Network). Uppsala University, Uppsala, Sweden, 30 May - 03 June, 2009. Available from: http://www.medsci.uu.se/klinbakt/ stigup/Projects/000\%20EE\%20SRH\%20N/09\%2006\%2030\%20EE\%2OSRH\%2OMeting\%20 Uppsala/07\%2010\%2013\%20CONF\%2OPRESENTATIONS.htm

21. Domeika M, Kligys G, Ivanauskiene O, Mereckiene J, Bakasenas V, Morkunas $B$, et al. Implementation of a national electronic reporting system in Lithuania. Euro Surveill. 2009;14(13):pij=19165. Available from: http://www. eurosurveillance.org/ViewArticle.aspx?ArticleId=19165

22. STIGUP (Sexually transmitted infections Uppsala group). Spring marathon of the Belarus STI project. In: Domeika M, Shimanskaya I. Editors. STIGUP Newsletter. 2008; 9:4. Available from: http://www.medsci.uu.se/klinbakt/stigup/ Newsletter.htm 